\title{
The Effects of Irreversibility and Uncertainty on Business Investments: A New View of Investment
}

\author{
Katarína Belanová \\ University of Economics in Bratislava \\ Dolnozemská Street 1, 85235 Bratislava, Slovakia \\ Katarina.belanova@euba.sk
}

\begin{abstract}
This article presents a survey of recent theoretical, as well as empirical, contributions concerning business investments, which help to explain the investment decision making of companies. These contributions emphasize the relevance of idiosyncratic factors affecting investment decisions such as the degree of irreversibility and uncertainty, interactions between these factors may generate an opportunity cost equivalent to the exercise of an option and so they add an important dimension to the neoclassical theory of investment (also called standard or orthodox theory of investment). This theory has not recognized the important qualitative and quantitative implications of this interaction, what can explain some of its failures. We investigate the irreversibility of investments and the impact this has on the nature of the relationship between investment and uncertainty in the way of empirical analysis. The empirical analysis uses firm level data and is based on a survey of 53 automotive suppliers, which was carried out during the year 2011. We find supportive evidence for the fact that uncertainty is negatively associated with planned investments of the companies surveyed, which remains true also in the presence of irreversibility. At the end we demonstrate the core of the real options approach in a form of a practical example.
\end{abstract}

Keywords: investment, uncertainty, irreversibility

JEL Classification: D81, D92

\section{Introduction}

It is generally known, that companies, as well as other economic entities, make capital investments in order to create and exploit profit opportunities. Understanding the investment decisions of companies is perhaps the most important for economic policy - makers, since fluctuations in investment activity are not without consequences for the rest of the national economy. Especially nowadays, in times of economic recession, this issue due to its relationship with the overall performance of the national economy and hence with the employment and growth, is getting back to the forefront.

However, despite its importance, investment behavior of firms, industries and countries is poorly understood and conventional structural models of business 
investment offer only fragile support for explanation and prediction of changes in capital expenditures of companies.

This may reflect the fact that available models have ignored potentially relevant features of investment behavior, namely that investment expenditures are often irreversible and may be delayed due to uncertainty surrounding the evolution of prices, costs and other market conditions relevant for investment decisions.

The turning point was at the end of the 1980s, when several authors stressed the importance of the possibility that investments are irreversible and that it affects the relationship between investment and risk (Bernanke, 1983; McDonald and Siegel, 1986; Bertola and Caballero, 1994; Dixit and Pindyck, 1994).

The article offers a number of valuable insights into how managers can evaluate opportunities, and it highlights a basic weakness of the standard net present value rule. We present the results of an empirical analysis, in which we investigate the irreversibility of investments and the impact this has on the nature of the relationship between investment and uncertainty. The article also shows how to include the value of the real options into the calculations of the effectiveness of the projects in a form of a practical example.

The remainder of the paper is organized as follows. Section 1 briefly summarizes the theoretical background and it is divided into two parts to highlight the difference between Orthodox theory of investments and Real options approach. Section 2 is dedicated to the results of the empirical studies concerning the issue as well as to the results of our empirical analysis. Section 3 is an application of the theoretical knowledge in a form of a practical example.

\section{Theoretical contribution}

\subsection{The orthodox theory}

Investment decisions of firms depend on a large number of factors, one of which may be the extent of uncertainty about future events. Uncertainty may well be an especially relevant factor in environments in which investors have difficulties in making predictions about the future, since the environment may be highly volatile and/or sufficient information to make predictions is difficult to obtain. The environment in which companies operate nowadays is very volatile and unpredictable due to growing globalization and rapidly advancing technology inducing changes in the market place. In addition, uncertainty may be a particularly relevant factor determining investment in developing and transition economies. These economies are generally more volatile by nature and information problems in these economies are more prevalent due to deficient markets and institutions.

The nature of the relationship between investment and uncertainty has received considerable attention in the literature. As Jorgenson (1971) noted in his survey 
"the most important open question in the study of investment is the integration of uncertainty into the theory and econometrics of investment." However, the theoretical literature on this issue is not conclusive on the sign of the relationship between investment and uncertainty.

Generally we can observe two main streams: standard and optional ones. Standard investment theory states that the strategy of the firm is to invest in a project only if the present value of expected cash flows from the investment exceeds the total costs. The value of the total costs may be referred to as the threshold value of the investment. In principle, it can be shown that the threshold value increases with the degree of uncertainty with respect to the future growth rate of sales, which means that greater uncertainty leads to lower willingness to invest. Uncertainty may either raise or lower the investment. The exact nature of the relationship crucially depends on the model specification used and the underlying assumptions with respect to the risk behaviour of the investor, the extent of competition in his output markets, the characteristics of the production technologies used and the shape of the adjustment costs. ${ }^{1}$

The NPV rule, however, is based on some implicit assumptions that are often overlooked. Most importantly, it assumes that either the investment is reversible, that is, it can somehow be undone and the expenditures recovered, should market conditions turn out to be worse than anticipated, or, if the investment is irreversible, it is a now or never proposition, that is, if the firm does not undertake the investment now, it will not be able to in the future (Dixit and Pindyck, 1994).

Although some investments meet these conditions, most do not. Irreversibility and the possibility of delay are very important characteristics of most investments in reality.

Since the late 1980s several authors have stressed the importance of the possibility that the investment is irreversible (i.e., taking into account the shape of the adjustment costs) and the impact of this on the investment - uncertainty relationship (Bernanke, 1983; McDonald and Siegel, 1986; Bertola and Caballero, 1994; Dixit and Pindyck, 1994). The fact that investment is (partly) irreversible increases the user cost of capital, thereby also leading to an increase of the threshold value of the investment. This can be shown by applying the option pricing model of investment. When investment in capital stock is (partly) irreversible, this introduces a so - called option value to postpone investment until later, when more information about relevant future events is available. If uncertainty is higher the value of the option to wait also increases, thus leading

1 Broad surveys of the literature on the relationship between investment and uncertainty can be found in Lensink, Bo and Sterken (2001) and Carruth, Dickerson and Henley (2000). 
to lower current investment layouts (Lombardi 2009; Bloom et al. 2007, Bond a Lombardi 2006). We dedicate more attention to these theretical advances in the next part of the paper (part 1.2).

It is necessary to mention, that Abel and Eberly (1994) and Caballero (1991) challenge this finding and stress that, under the assumption of competitive markets and constant returns to scale, uncertainty may not necessarily lead to lower investment, even in the presence of irreversibility. They show that the relationship between investment and uncertainty depends on both the degree of irreversibility and competition and, more particularly, on the way these two factors are interrelated. They argue that the relationship between investment and uncertainty may be represented by an inverted $U$ - curve: at low levels of uncertainty, the relationship between investment and uncertainty may be positive, whereas at high levels of uncertainty it starts to be negative. According to them, it is due to the fact that uncertainty has both a user - cost and a so called hangover effect on investment.

The above discussion of the main theoretical contributions to the literature on the relationship between investment and uncertainty shows that this relationship may go either way, and the actual relationship will vary depending on firm - specific circumstances regarding competition, cost functions and technology.

\subsection{Recent theoretical advances: the real option approach}

As stated above, irreversibility and the possibility of delay are very important characteristics of most investments in reality. Irreversibility usually arises because capital is industry or firm specific, i.e., it cannot be used productively in a different industry or by a different firm. A steel plant, for example, is industry specific. It can only be used to produce steel, so if the demand for steel falls, the market value of the plant will fall. Although the plant could be sold to another steel company, there is likely to be little gain from doing so, so the investment in the plant must be viewed as a sunk cost. As another example, most investments in marketing and advertising are firm specific, and so are likewise sunk costs. Partial irreversibility can also result from the "lemons" problem. Office equipment, cars, trucks, and computers are not industry specific, but have resale value well below their purchase cost, even if new.

Irreversibility can also arise because of government regulations or institutional arrangements. For example, capital controls may make it impossible for foreign (or domestic) investors to sell assets and reallocate their funds. And investments in new workers may be partly irreversible because of high costs of hiring, training, and firing.

Firms do not always have an opportunity to delay investments. There can be occasions, for example, in which strategic considerations make it imperative for a firm to invest quickly and thereby preempt investment by existing or potential 
competitors. But in most cases, delay is at least feasible. There may be a cost to delay - the risk of entry by other firms, or simply foregone cash flows - but this cost must be weighed against the benefits of waiting for new information.

The ability to delay an irreversible investment expenditure can profoundly affect the decision to invest. It also undermines the simple NPV rule, and hence the theoretical foundation of standard neoclassical investment models. The reason is that a firm with an opportunity to invest is holding an "option" analogous to a financial call option - it has the right but not the obligation to buy an asset at some future time of its choosing. As a consequence, option pricing theory can be used to "price" investment decisions and decide on optimal timing of exercise. This gave rise to a large body of new literature, and a new class of models usually referred to as "real options" models. Viewing the investment decision as exercising an investment option can be illustrated most simply by referring to the conventional NPV rule. ${ }^{2}$ Like a financial option, the option itself has some (non negative) value, denoted as $F_{0}$ in the following, a.o. because of uncertainty over the future value of the investment project. The direct pay - off from investing is given by $\mathrm{V}-\mathrm{I}$, where $\mathrm{V}$ is the present value of the investment project and $\mathrm{I}$ the investment cost (the classical NPV criterion). When this pay - off is positive, it is worthwhile to invest. However, once the investment is made, the option is gone, so the value of the option today $\left(F_{0}\right)$ must be considered as an opportunity cost of investing, and hence must be added to the investment cost (I). Hence the optimal investment criterion is modified into:

$\mathrm{V}<\mathrm{I}+\mathrm{F}_{0}$ : wait to invest

$\mathrm{V} \geq \mathrm{I}+\mathrm{F}_{0}$ : invest

Another way of indicating the same criterion is stating that the value of the project, V, must exceed the investment cost, I, by at least the value of the option, $F_{0}$, in order to decide to invest now. This minimum - acceptable project value is generally called the "threshold value" of investment, in the following denoted as $\mathrm{V}^{*}$.

In option pricing jargon, the option is said to be "out of money" in the first case (waiting) and "in the money" when the underlying value of the investment (V) exceeds the option value (price) plus the investment cost. The basic new insight is in fact that one should wait until the orthodox NPV is "very large", with F putting an exact value to it. As such, the basic investment decision to take is not whether or not to invest (as indicated by the orthodox NPV - rule), but rather

\footnotetext{
${ }^{2}$ According to Cassimon et al. (2002).
} 
when to invest, i.e. determining the optimal moment of exercising the investment option. ${ }^{3,4}$ This intuitive reasoning is graphically represented in Figure 1.

Figure 1 Real option analysis (ROA) versus the net present value rule (NPV)

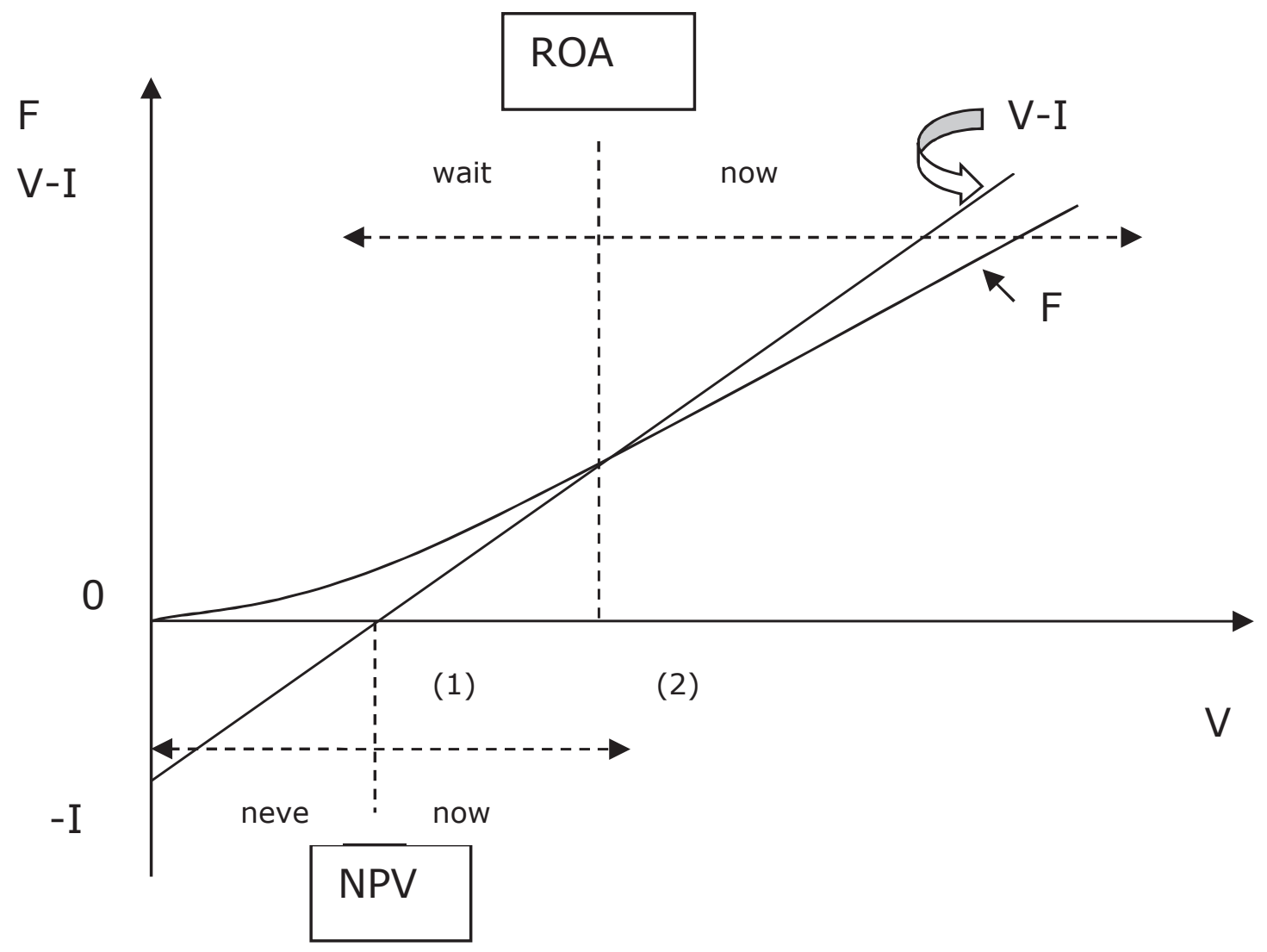

Source: Cassimon et al. (2002).

From the viewpoint of the subject of this paper, the most important consequence resulting from this model solution is that uncertainty (and irreversibility) introduces a difference between the minimum - acceptable value of the project in order to invest $\left(\mathrm{V}^{*}\right)$ and the cost of investment (I). Even more important, the higher level of uncertainty, the more the value of the investment opportunity must exceed its cost before the investment takes place. As such, the individual investment decision is, in theory, very dependent on the level of uncertainty. The result is that changing economic conditions that affect the perceived riskiness of future cash flows can have a large impact on investment spending, larger than,

\footnotetext{
${ }^{3}$ From the previous paragraphs, it is clear that the orthodox NPV criterion is no longer valid for "real option" investments. But whether this must be considered as a new theory of investment or a correction of the old paradigm remains open and is in fact less important, as indicated also by Dixit and Pindyck (1994).

${ }^{4}$ We deal with the option to wait in this article. There are more kinds which can be taken into account. For more information, see for example Belanová, 2010.
} 
say, a change in interest rates. This may help to explain why neoclassical investment theory has so far failed to provide good empirical models of investment behavior, and has led to overly optimistic forecasts of effectiveness of interst rate and tax policies in stimulating investment.

The option insight also helps explain why the actual investment behavior of firms differs from the wisdom taught in business schools. Firms invest in projects that are expected to yield a return in excess of a required, or "hurdle", rate. Observers of business practice find that such hurdle rates are typically three or four times the cost of capital. ${ }^{5}$ In other words, firms do not invest until price rises substantially above long - run average cost. On the downside, firms stay in business for lengthy periods while absorbing operating losses, and price can fall substantially below average variable cost without inducing disinvestment or exit.

\section{Empirical studies}

As we could see, the relationship between investment and uncertainty and the role of irreversibility is not clear from a theoretical point of view. On the other hand, empirical studies generally have found a negative effect of uncertainty on investment when taking into account the irreversibility of investment. ${ }^{6}$ These studies take different approaches in analysing the relationship. In particular, they differ with respect to how they measure uncertainty and irreversibility and, related to these measurement issues, with respect to whether they use data at the industry or firm level. Moreover, they mostly focus on developed economies.

Concerning measuring of uncertainty, we can distinguish several groups of authors according to the selected measures. Several authors have used standard measures of risk - such as standard deviation, variance or coefficient of variation - of a variable that is considered to be crucial for investment decisions as their measure of uncertainty (Bell and Campa, 1997; Pindyck, 1986; Ogawa and Suzuki, 2000). Other authors have taken GARCH estimates of conditional variances of such crucial variables as proxies for uncertainty (Episcopos, 1995; Price, 1996). Another group of authors has measured the volatility of a particular variable using AR model residuals (Ghosal and Loungani, 1996). Finally, some studies have used firms ' perceptions about future developmets of a particular variable determining investment as their uncertainty measure (Guiso and Parigi, 1999; Pattillo, 1998; Bond a Lombardi, 2006; Bloom, Bond a Reenen, 2007).

\footnotetext{
${ }^{5}$ The hurdle rate appropriate for investments with systematic risk will exceed the riskless rate, but not by enough to justify the numbers used by many companies.

6 The empirical literature on the relationship between investment and uncertainty is quite extensive. Many of these studies find a negative relationship and explain this by referring to the irreversibility hypothesis. This review of the empirical literature focuses on studies that analyse the relationship between investment and uncertainty and use irreversibility to explain their outcomes.
} 
Variables that have been considered as being crucial in empirical studies are, among others, exchange rates, input prices, shared returns, output demand and output prices (Carruth, Dickerson and Henley, 2000).

Irreversibility has been measured, either directly by using information on the degree of access to second - hand markets of used capital (Guiso and Parigi, 1999) or the ratio of the resale value to the replacement value of capital (Pattillo, 1998), or indirectly by defining different types of investment for which different degrees of irreversibility are assumed, such as greenfield investments versus capacity expansion (greenfield investment is considered to be less reversible; Bell and Campa, 1997), material versus machinery industry (investment made by firms in the materials industry is assumed to be less reversible; Ogawa and Suzuki, 2000) and $R$ \& D investment versus non - R\&D investment ( $R \& D$ investment is assumed to be less reversible; Goel and Ram, 2001).

Empirical studies also differ with respect to whether they use an aggregate or disaggregate empirical analysis. Some authors make use of the data at the country level (Goel and Ram, 2001). Other studies use aggregate data at the industrial sector level (Bell and Campa, 1997; Goel and Ram, 1999). Finally, several studies make use of firm - level data (Ogawa and Suzuki, 2000; Guiso and Parigi, 1999; Bond a Lombardi, 2006; Bloom, Bond a Reenen, 2007; Pattillo, 1998; Le, Hermes and Lanjouw, 2004; Belanová, 2012).

As Le, Hermes and Lanjouw (2004) state in their study, a proper analysis of the relationship between investment and uncertainty should make use of firm - level data, since theoretical models indicate that the relationship between investment and uncertainty depends on firm - specific characteristics. At least part (if not most) of the uncertainty affecting a firm 's investment decisions will be due to idiosyncratic events, which will disappear when uncertainty is considered at the aggregate level due to the canceling out of different shocks for different firms. Moreover, the analysis should make use of survey data containing information on the expectations of decision - makers about the future values of variables that influence their investment decision. Only with this kind of information can the subjective perception (i.e., conditional on firm's own information set) of uncertainty be measured (e.g., an ex ante measurement of uncertainty) and this is the relevant determinant of investment decisions. Yet, most studies use ex post measures of uncertainty, because it is difficult and time consuming to obtain survey data on decision - makers' perceptions of uncertainty.

Among the studies that have investigated the investment - uncertainty nexus and have focused on irreversibility, only some of them use survey data to construct uncertainty measures based on subjective perceptions of agents. Guiso and Parigi (1999) use data based on a survey among Italian manufacturing firms. They measure uncertainty based on the perception of firms about future product demand. They find a negative relationship between investment and uncertainty 
and show that the degree of irreversibility influences this relationship: the negative relationship is stronger for firms for which the degree of irreversibility is higher. Bond and Lombardi (2006) test the effects of real options induced by risk and irreversibility of fixed capital on a sample of Italian firms. They make use of the expectations of the companies about future investments. Different from Guiso and Parigi (1999), their measure of risk allows them to determine the long - term impact of risk on capital accumulation, and so to examine the dynamics of investment. They demonstrate slower response of investment to demand shocks at a higher risk level. Bloom, Bond and Reenen (2007) came to similar conclusions by the investigation of British companies. They find a convex effect of demand shocks on investment decisions. Pattillo (1998) uses firm - level data from a panel of manufacturing firms in Ghana and focuses on the role played by the irreversibility of investment in determining the relationship between investment and uncertainty. She also finds evidence for the fact that the irreversibility of investment leads to lower investment under uncertain conditions. Le, Hermes and Lanjouw (2004) use empirical analysis, which is based on a survey of 210 rice-milling firms in Vietnam, firm-level data. They show that uncertainty reduces investment of rice millers in the presence of irreversibility, as is predicted by the real options approach to investment. They do not find evidence that the negative association between uncertainty and investment is influenced by the degree of irreversibility.

\subsection{Results of an empirical study in Slovakia}

As mentioned, there are only few studies using the information from transition or developing economies. Yet, investigating the investment - uncertainty relationship seems to be particlularly relevant in the context of these economies. That is why we investigated whether the irreversibility of investment has an impact on the nature of the relationship between investment and uncertainty for automotive suppliers in the SR. We used the following specification of investment behavior: ${ }^{7}$

$$
I_{i}=\alpha_{1}+\alpha_{2} S A L_{i, 2010}+\alpha_{3} P R O_{i, 2010}+\alpha_{4} V K S_{i}+\alpha_{5} N E Z_{i}+\varepsilon_{i}
$$

where:

- $\mathrm{I}_{1}$ - is total planned (gross) investment divided by total fixed assets in 2010,

- $\mathrm{SAL}_{2010}$ - is total sales in 2010 divided by total fixed assets in 2010 and reflects the accelerator model of investment, since past sales may reflect future investment opportunities; therefore we expect $a_{2}$ to be positive;

- $\mathrm{PRO}_{2010}$ - is total profit in 2010 divided by total fixed assets in 2010 and measures the existence of financial constraints with which automotive

\footnotetext{
7 According to Le, Hermes and Lanjouw (2004)
} 
suppliers may be confronted; we expect $a_{3}$ to be positive reflecting the importance of the availability of internal funds in determining investment decisions, which is taken as evidence for the existence of financial constraints for automotive suppliers when deciding on future investment,

- VKS - is the uncertainty variable; based on the theoretical literature as discussed in Section 1 of this paper, $a_{4}$ may be either positive or negative,

- NEZ - is our measure of irreversibility; we expect $a_{5}$ to be positive: the higher NEZ, the lower the irreversibility of investment, which according to the real options approach to investment decisions would suggest higher levels of planned investment.

The empirical model was estimated using the simple OLS technique based upon information about 53 automotive suppliers that we obtained from the survey.

We find supportive evidence for the fact that uncertainty is negatively associated with planned investments of the companies surveyed, which remains true also in the presence of irreversibility.

\section{Application}

\subsection{Description of the problem and entry data}

A company considers whether it should buy the licence for a production of a new line of luxury face creams. It is quite cheap nowadays according to the fact that it is possible to get one of the ingredients only in an area with civil unrest. The improvement of the situation is expected within 3 years. Capital outlay is 1 mil. f.u. and it is expected to generate yearly cash flow of 300,000 f.u. for 4 years by the discount rate $12 \%$ and non - risk rate $5 \%$. Volatility in the sector is characterized by a $50 \%$ standard deviation.

\subsection{Aim of the application}

The aim of the application is to determine:

a) NPV in a case of standard theory (i.e. without real option)

b) The value of the real option and so the NPV with this value (strategic NPV).

\subsection{Solution}

\subsubsection{Evaluation of the project in a case of standard NPV}

In this case we adjust the value of the project for the planned investment outlays. That means, if the project is implemented immediately, NPV is $-88,796$ f.u. 


\subsubsection{Evaluation of the project incorporating the value of the real options}

In this case we evaluate the licence as a call option for the realization of the future cash flows.

We use the formula for the calculation of the value of call option:

$$
C=\sum \frac{C F}{(1+i)^{t}} \cdot N\left(d_{1}\right)-C_{0} \cdot e^{-r t} \cdot N\left(d_{2}\right)
$$

while

$$
\begin{aligned}
& d_{1}=\frac{\ln \left(\sum \frac{C F}{(1+i)^{t}} / C_{0}\right)+\left(r+\sigma^{2} / 2\right) \cdot t}{\sigma \cdot \sqrt{t}} \\
& d_{2}=d_{1}-\sigma \cdot \sqrt{t}
\end{aligned}
$$

where CF - cash flow in each year

i - discount rate

$\mathrm{C}_{0}$ - capital outlay

$r$ - non - risk rate

$\sigma-$ standard deviation.

When we insert the required data, we get $d_{1}=0,498$ and $d_{2}=-0,367$. The values $N\left(d_{1}\right)$ and $N\left(d_{2}\right)$ can be found in the statistical tables for normal distribution function. In our example we have: $N\left(d_{1}\right)=0,691$ and $N\left(d_{2}\right)=0,365$.

We get the value of the licence incorporating the possibility of flexibility in decision making according to the changes in the environment characterized by the certain volatility by putting the data to the formula for the value of the call option.

$$
C=911,205 \cdot 0.691-1,000,000 \cdot 0.356 \cdot e^{-0.05 \cdot 3}=323,230.6 f . u .
$$

So the strategic NPV is $234,434.6$ f.u.

\subsection{Interpretation of the results}

It is obvious, that when we evaluate the project with the standard NPV rule, it is not acceptable. When we incorporate also the value of the real option, then the strategic NPV is positive. This value does not exclude the purchase of the licence if its price was lower than the calculated estimation of the strategic NPV. Anyway, the project should be carufully considered and evaluated by the sensitivity analysis as well. 


\section{Conclusion}

In this paper we have surveyed recent developments in the literature on business investment that have shed light on important aspects of firms ' investment behaviour. A common feature of the theoretical contributions is to emphasize the relevance of idiosyncratic factors affecting investment decisions. Some of these factors relate to specific features of an investment project, such as its degree of irreversibility and uncertainty, whose interaction may generate an opportunity cost equivalent to the exercise of a (real) option. Overall, these new contributions add an important dimension to the traditional neoclassical theory of investment in so far as they emphasize cross - sectional differences in optimal investment behaviour.

We presented the results of an empirical analysis, which makes a contribution to the existing empirical literature. There are only a few other studies which have used information from transition or developing economy, although investigating the investment - uncertainty relationship seem to be particularly relevant in the context of these economies, since they are generally more volatile by nature. We find supportive evidence for the fact that uncertainty is negatively associated with planned investment of automotive suppliers in the SR. Moreover, we show that this remains true given the presence of irreversibility.

At the end of the paper we demonstrate that when we incorporate the value of the real option into evaluation of effectiveness of investment, the conclusion according to the standard NPV rule can be changed. The value of the real option increases the value of the project.

\section{References}

Abel, A. B., Eberly, J. C. (1994). A Unified Model of Investment under Uncertainty. American Economic Review, vol. 5, pp. 1369-1384.

Belanová, K. (2012). Investície, riziko a nezamenitel'nost' investícií: príklad automobilového priemyslu v SR. Ekonomický časopis, vol. 2, pp. 187-209.

Belanová, K. (2010). Teória a politika podnikatel'ských financií. Bratislava: Vydavatel'stvo EKONÓM.

Bell, G. K., Campa, J. M. (1997). Irreversible Investment and Volatile Markets: A Study of the Chemical Processing Industry. Review of Economics and Statistics, vol. 1 , pp. 79-87.

Bernanke, B. S. (1983). Irreversibility, Uncertainty and Cyclical Investment. Quarterly Journal of Economics, vol. 1, pp. 85-106.

Bertola, G., Caballero, R. J. (1994). Irreversibility and Aggregate Investment. Review of Economic Studies, vol. 2, pp. 223-246. 
Bloom, N., Bond, S., Reenen, J. (2007). Uncertainty and Investment Dynamics. Review of Economic Studies, vol. 2, pp. 391-415.

Bond, S. R., Lombardi, D. (2006). To Buy or Not to Buy? Uncertainty, Irreversibility, and Heterogeneous Investment Dynamics in Italian Company Data. IMF Staff Papers, No. 53, Washington, DC.

Caballero, R. J. (1991). On the Sign of the Investment - Uncertainty Relationship. American Economic Review, vol. 4, pp. 279-288.

Carruth, A., Dickerson, A., Henley, A. (2000). What do We Know about Investment under Uncertainty? Journal of Economic Surveys, vol. 2, pp. 119-153.

Cassimon, D. et al. (2002). Investment, Uncertainty and Irreversibility: Evidence from Belgian Accounting Data. Working papers, Belgium.

Dixit, A. K., Pindyck, R. S. (1994). Investment under Uncertainty. New Yersey: Princeton University Press.

Episcopos, A. (1995). Evidence on the Relationship between Uncertainty and Irreversible Investment. Quarterly Journal of Economics and Statistics, vol. 1, pp. 41-52.

Ghosal, V., Loungani, P. (1996). Product Market Competition and the Impact of Price Uncertainty on Investment: Some Evidence from US Manufacturing Industries. Journal of Industrial Economics, vol. 2, pp. 217-228.

Goel, R. K., Ram, R. (2001). Irreversibility of R\&D Investment and the Adverse Effect of Uncertainty. Economics Letters, vol. 2, pp. 287-291.

Guiso, L., Parigi, G. (1999). Investment and Demand Uncertainty. Quarterly Journal of Economics, vol. 1, pp. 185-227.

Jorgenson, D. W. (1971). Econometric studies of investment behavior: A survey. Journal of Economic Literature, vol. 4, pp. 111-147.

Le, K. N., Hermes, N., Lanjouw, G. (2004). Investment, Uncertainty and Irreversibility. Economics of Transition, vol. 2, pp. 333-336.

Lensink, R., Bo, H., Sterken, E. (2001). Investment, Capital Market Imperfections, and Uncertainty: Theory and Empirical Results. Cheltenham: Edward Elgar.

McDonald, R., Siegel, D. (1986). The Value of Waiting to Invest, Quaterly Journal of Economics. Vol. 4, pp. 707-728.

Ogawa, K., Suzuki, K. (2000). Uncertainty and Investment: Some Evidence from the Panel Data of Japanese Manufacturing Firms. Japanese Economic Review, vol. 2, pp. 170-192. 
Pattillo, C. (1998). Investment, Uncertainty, Irreversibility in Ghana. IMF Staff Papers, No. 45, Washington, DC.

Pindyck, R. S. (1986). Capital Risk and Models of Investment Behaviour. Working Paper, No. 1819, Cambridge.

Price, S. (1996). Agregate Uncertainty, Investment and Assymetric Adjustment in the UK Manufacturing Sector. Applied Economics, vol. 11, pp. 1369- 1379. 